\title{
O DIREITO CONSTITUCIONAL À INCLUSÃO DO DEFICIENTE AUDITIVO NA REDE REGULAR DE ENSINO: UM ESTUDO DE SUA EFICÁCIA NO MUNICÍPIO DE CAMPOS NOVOS
}

\section{Liana Débora Ramos}

Resumo: $O$ presente artigo tem por objetivo estudar a situação das pessoas portadoras de deficiência auditiva, fazendo uma análise acerca da inclusão desses indivíduos na rede regular de ensino do município de Campos Novos-SC. Procurou-se, através de uma pesquisa bibliográfica e de campo, saber como está se dando a inclusão escolar desses alunos com necessidades educacionais especiais, de modo a descobrir se as escolas e os professores do município foco da pesquisa estão preparados para concretizar a inclusão que a Constituição Federal de 1988 estabelece. Concluiu-se que muito há que se fazer ainda para a efetivação da inclusão, uma vez que as escolas visitadas não se mostraram totalmente capazes de promover essa garantia constitucional. Assim, pôde-se observar que a norma constitucional, apesar de ser um direito fundamental (direito à educação), é carente de eficácia social, que se trata da concretização da lei ao fim a que ela se destina.

Palavras-chave: Deficiente auditivo. Inclusão. Educação. Rede regular de ensino.

1 Advogada, Aluna da Escola Superior da Magistratura de Santa Catarina, Bacharel em Direito pela UNOESC - Universidade do Oeste de Santa Catarina, Licenciada em Pedagogia e Supervisão Escolar pela UNITINS - Fundação Universidade do Tocantins. E-mail: liarams@bol.com.br 


\section{INTRODUÇÃO}

A inclusão dos alunos deficientes auditivos na rede regular de ensino, apesar de estar regulamentada na nossa Carta Magna desde 1988, está sendo uma novidade e um grande desafio para as escolas brasileiras.

Esses alunos são novos sujeitos de direito, eis que os profissionais da educação do Brasil estão, recentemente, tentando tornar uma realidade esta "garantia constitucional de inclusão."

Existem muitas discussões acerca da inclusão dos portadores de necessidades especiais na rede regular de ensino.

O presente estudo tem por objetivo a análise dos direitos garantidos aos deficientes auditivos e a aplicabilidade da inclusão deles na rede regular de ensino.

A análise partirá de um estudo da Constituição Federal, da legislação específica, de bibliografias e de uma pesquisa de campo, por meio do método de observação e entrevista em seis escolas do município de Campos Novos-SC.

Assim, com este trabalho, verificar-se-á a situação dos deficientes auditivos que estão inseridos na rede regular de ensino de Campos Novos, além de analisar se esses alunos estão fazendo parte de uma verdadeira "inclusão" ou se estão apenas inseridos nas escolas para responder a um anseio da sociedade, a qual, ao invés de incluí-los, socializa-os.

\section{QUESTÕES SOCIAIS E JURÍDICAS SOBRE A INCLUSÃO DOS DEFICIENTES AUDITIVOS NA REDE REGULAR DE ENSINO}

De início, cumpre discorrer acerca de algumas definições, tais como o princípio da igualdade e o ideal de inclusão dos portadores de necessidades especiais.

A Constituição Federal do Brasil tem como princípio fundamental o da igualdade, pois dispõe em seu artigo $5^{\circ}$, que "todos são iguais perante a lei, sem distinção de qualquer natureza, garantindo-se aos brasileiros e aos estrangeiros, residentes 
no País, a inviolabilidade do direito à vida, à liberdade, à igualdade, à segurança e à propriedade.”

O princípio da igualdade, em suma, prevê que os cidadãos tenham tratamento idêntico pela lei, de acordo com os critérios que o ordenamento jurídico protege. Assim, o que se proíbe são as discriminações arbitrárias e absurdas, eis que o tratamento desigual dos casos desiguais, na medida em que se desigualam, é exigência corriqueira do próprio conceito de Justiça. Para a efetivação da igualdade é necessário que as certas liberdades, que têm por objetivo a igualdade de condições sociais, sejam alcançadas, não só por meio de leis, mas também pela aplicação de políticas e/ou programas governamentais. (MORAES, 2005, p. 31).

Já dizia Ruy Barbosa que: "a regra da igualdade não consiste senão em aquinhoar desigualmente aos desiguais, na medida em que se desigualam. Nesta desigualdade social, proporcionada à desigualdade natural, é que se acha a verdadeira lei da igualdade." (AMORIM, 2002). ${ }^{2}$

$\mathrm{Na}$ área jurídica, uma das maiores preocupações é a eficaz aplicação do princípio da igualdade para se alcançar a justiça. Essa não é uma tarefa simples, pois o grande dilema é saber em qual hipótese tratar igualmente o igual e desigualmente o desigual.

Entretanto, a igualdade transcende o mundo jurídico, de modo que todo ato de desigualdade (que cause prejuízo à pessoa enquanto cidadão), infringindo ou não a legislação, deve ser repudiado pela sociedade. Esta ideologia vem ao encontro do tema "inclusão dos portadores de necessidades especiais", ao passo que eles também necessitam da proteção do princípio da igualdade para serem incluídos na sociedade.

2 "Para que a igualdade seja real, entretanto, ela há que ser relativa (dar tratamento igual aos iguais e desigual aos desiguais). O que isso significa? As pessoas são diferentes, têm necessidades diversas e o cumprimento da lei exige que a elas sejam garantidas as condições apropriadas de atendimento às peculiaridades existentes. Tratar desigualmente não se refere à instituição de privilégios, e sim, à disponibilização das condições exigidas pelas peculiaridades individuais na garantia da igualdade real." (MANZINI, [org.], 2000, p. 2). 
Como se pode observar, a ideia de inclusão se fundamenta numa filosofia que reconhece e aceita a diversidade na vida em sociedade. Isto significa garantia do acesso de todos a todas as oportunidades, independentemente das peculiaridades de cada indivíduo e/ou grupo social.

A palavra inclusão na sociedade brasileira é "sinônimo" de desafio, por se tratar de uma sociedade intrinsecamente preconceituosa.

Cabe salientar, então, que os indivíduos portadores de deficiência são sujeitos de direito, capazes de interagir com a sociedade, dentro de suas limitações. Por esse motivo, eles não podem sofrer preconceitos, devem ter oportunidades de educação, emprego, saúde, cultura, lazer e demais benefícios pertinentes a todo cidadão.

Ferreira (2006) traz a informação de que, "segundo dados da $\mathrm{ONU}$, cerca de $10 \%$ da população é constituída por pessoas portadoras de alguma deficiência. Não obstante esse elevado número e a sua existência desde os tempos mais remotos, verifica-se que a nossa legislação constitucional nem sempre contemplou esta parcela da comunidade. E quando se fala em cidadania a fonte primária é a Constituição.”

O processo de inclusão dos alunos deficientes é difícil de ser realizado apenas com uma previsão legal, pois as pessoas portadoras de necessidades especiais não foram criadas numa sociedade inclusiva e nem se encontram, ainda, num meio totalmente sem preconceitos.

Em que pese a difícil situação, e quando a própria deficiência permite, os portadores de necessidades especiais procuram interagir com a sociedade, vencendo honrosamente as imensas dificuldades que surgem diariamente. Com isso, há uma inversão na forma que a inclusão social se concretiza, eis que não é a sociedade que se adapta para receber o deficiente, mas sim, a pessoa deficiente que se adapta para se integrar ao meio. Logo, as pessoas com deficiências se deparam, em seu dia a dia, com o binômio exclusão-inclusão, o qual aparentemente 
é contrário, mas se harmoniza no tocante a demonstração de potencialidades, ou seja, quando o indivíduo supera barreiras. A pessoa portadora de necessidade especial não deseja bondade alheia, mas sim, o respeito a sua dignidade humana e o reconhecimento de suas qualidades, bem como o respeito ao exercício de sua cidadania. (BOLONHINI, 2004, p. 34).

Perpassada essa breve introdução acerca do princípio da igualdade e do ideal de inclusão dos portadores de necessidades especiais, é oportuno discorrer sobre os direitos humanos e fundamentais.

Todas as pessoas são titulares de direitos em se tratando de direitos humanos, uma vez que o fundamento de tais direitos é o próprio ser humano e suas necessidades essenciais.

Conforme estabelece Herkenhoff (2002, p. 10), há muito tempo os direitos humanos se destacam nas diversas fases da história, tendo, inclusive, um papel importantíssimo nos dias de hoje. Uma das peculiaridades dos direitos humanos é que eles foram tomados como bandeira por todos os oprimidos da Terra. Ao ler os jornais ou acompanhar as lutas populares fica fácil de constatar isto. Indivíduos, grupos, classes, nações, minorias de toda ordem espalhados pelos mais diversos lugares do mundo, recorrem aos direitos humanos na batalha de todos os dias.

Ramos (2005, p. 19) entende "por direitos humanos um 'conjunto mínimo de direitos necessários para assegurar a vida do ser humano baseada na liberdade, igualdade e na diversidade"”.

Foram necessários muitos séculos para que a primeira organização internacional que uniu a quase-totalidade dos povos proclamasse que todos os homens nascem livres e iguais em dignidade e direitos, através da Declaração Universal dos Direitos Humanos. Tal Declaração foi aprovada pela Assembléia Geral das Nações Unidas, em 10 de dezembro de 1948, sendo que ela organizou toda uma teoria ao proclamar em seu artigo VI que todo homem tem direito de ser, em todos os lugares, reconhecido como pessoa. (COMPARATO, 2003, p.12 e 32). 
O reconhecimento Universal dos Direitos Humanos teve como consequência o surgimento dos direitos fundamentais, que são um conjunto institucionalizado de direitos e garantias do homem, cujo objetivo principal é o respeito a sua dignidade através de seu amparo frente ao arbítrio do poder estatal, bem como a promoção de condições mínimas de vida e de desenvolvimento da personalidade de todos. (MORAES, 1997, p. 39).

Acerca do surgimento dos direitos fundamentais, Moraes (1997, p. 19) dispõe que:

Os direitos humanos fundamentais, em sua concepção atualmente conhecida, surgiram como produto da fusão de várias fontes, desde tradições arraigadas nas diversas civilizações, até a conjugação dos pensamentos filosófico-jurídicos, das idéias surgidas com o cristianismo e com o direito natural. Essas idéias encontravam um ponto fundamental em comum, a necessidade de limitação e controle dos abusos de poder do próprio Estado e de suas autoridades constituídas e a consagração dos princípios básicos da igualdade e da legalidade como regentes do Estado moderno e contemporâneo. Assim, a noção de direitos fundamentais é mais antiga que o surgimento da idéia de constitucionalismo, que tão-somente consagrou a necessidade de insculpir um rol mínimo de direitos humanos em um documento escrito, derivado diretamente da soberania popular.

Sarlet (2007, p. 91) estabelece o conceito de direitos fundamentais da seguinte forma:

Direitos fundamentais são, portanto, todas aquelas posições jurídicas concernentes às pessoas, que, do ponto de vista do direito constitucional positivo, foram, por seu conteúdo e importância (fundamentalidade em sentido material), integradas ao texto da Constituição e, portanto, retiradas da esfera de disponibilidade dos poderes constituídos (fundamentalidade formal), bem como as que, por 
seu conteúdo e significado, possam lhes ser equiparados, agregando-se à Constituição material, tendo, ou não, assento na Constituição formal (aqui considerada a abertura material do Catálogo).

Nos dias de hoje, é inaceitável que um Estado Democrático de Direito não tenha como um de seus alicerces os direitos fundamentais. Os Estados modernos têm reconhecido esses direitos em suas constituições, ou, ao menos, aderindo a algum dos importantes pactos internacionais concernentes aos direitos fundamentais. (NUNES, 2007, p. 15).

Quanto aos direitos fundamentais, estes são normas de aplicabilidade direta e eficácia plena, que é quando a norma se aplica independentemente de providências legislativas. Essa aplicabilidade é determinada pelo $\S 1^{\circ}$, do art. $5^{\circ}$, da $\mathrm{CF}$, o qual reza que "as normas definidoras dos direitos e garantias fundamentais têm aplicação imediata”.

Segundo Sarlet (2007, p. 268), apesar das reconhecidas doutrinas dos autores brasileiros como José Afonso da Silva e Maria Helena Diniz classificarem as normas constitucionais em normas de: eficácia plena, limitada e contida, todas as normas constitucionais têm um mínimo de eficácia, especialmente aquelas que tratam de direitos fundamentais, em razão do art. $5^{\circ}, \S 1^{\circ}$, da CF. Assim, os preceitos constitucionais possuem certa eficácia jurídica e aplicabilidade, mesmo aqueles de cunho programático.

Portando, a norma jurídica que vige sempre vai ser potencialmente aplicável, ou seja, apta a produzir efeitos. Na realidade, o problema da eficácia envolve a eficácia jurídica e a social, uma vez que as duas são indispensáveis para a concretização do direito.

Todavia é importante salientar que há normas programáticas na Carta Magna, que são as normas que precisam de uma atuação dos órgãos estatais e do legislador para a sua concretização, onde deverão ser estabelecidos os meios e as formas a serem utilizadas pelo Estado. Tais normas, conforme já dito, 
também possuem certa eficácia e aplicabilidade, e há quem diga que as normas programáticas têm função importante dentro da ordem constitucional, servindo como válvulas de natureza ideológica, representadas pelas atividades políticas estabelecidas em razão do momento constituinte, objetivando cuidar das necessidades dos diferentes grupos sociais. (SARLET, 2007, p. 279-280).

A título de esclarecimento, Diniz (2001, p. 116) define as normas programáticas como:

As normas constitucionais programáticas são as em que o constituinte não regula diretamente os interesses ou direitos nelas consagrados, limitando-se a traçar princípios a serem cumpridos pelos poderes públicos (Legislativo, Executivo e Judiciário) como programas das respectivas atividades, pretendendo unicamente a consecução dos fins sociais pelo Estado.

A norma contida no artigo $5^{\circ}, \S 1^{\circ}$, da $\mathrm{CF}$, segundo a doutrina, estabelece a vinculação dos órgãos públicos e particulares ao cumprimento dos direitos fundamentais. O Judiciário, porém, tem o poder/dever de aplicar imediatamente as normas sobre direitos e garantias fundamentais, garantindo-lhes a sua eficácia. A disposição que os direitos fundamentais são diretamente aplicáveis, todavia, deve ser analisada com cuidado, não podendo ser acolhida de imediato, pois, apesar da regra geral estabelecer que o judiciário pode e deve assegurar os direitos fundamentais com o preenchimento de lacunas, isso não significa que não há limites para essa regra. Os limites existem, como, por exemplo, os limites da reserva do possível, da falta de legitimação dos tribunais para a aplicação de alguns programas socioeconômicos, assim como o conflito com outros direitos fundamentais, que influirão na análise da aplicação do dispositivo da aplicabilidade imediata do art. 5a,$\S 1^{\circ}$, da CF. (SARLET, 2007, p. 282-283).

O direito à educação, que é tratado no presente trabalho, também é um direito fundamental, definido no art. 6º da Carta 
Magna. Tal direito também está previsto no art. 205 da CF, que assim dispõe:

Art. 205. A educação, direito de todos e dever do Estado e da família, será promovida e incentivada com a colaboração da sociedade, visando ao pleno desenvolvimento da pessoa, seu preparo para o exercício da cidadania e sua qualificação para o trabalho.

A técnica de positivação utilizada para estabelecer o direito à educação demonstra a sua qualidade de norma programática, sem deixá-la carente de eficácia. (SARLET, 2007, p. 270).

O problema reside nas normas constitucionais definidoras dos direitos sociais, que precisam para a concretização de seus valores e efetividade, tanto semântica como pragmaticamente, de uma atuação positiva do Estado. Sendo o direito à educação uma norma definidora de direitos, o Estado tem obrigação de atuar positivamente na criação políticas públicas específicas de cunho social, a fim de concretizar o direito constitucionalmente assegurado. No caso da educação, já há na Constituição dispositivos que vinculam recursos e geram direitos subjetivos à população, a qual pode cobrar do governo uma atuação positiva nos setores sociais com a criação de políticas públicas específicas. Desta forma, alguns direitos sociais possuem uma eficácia plena e imediata ou, ao menos, uma efetividade plena e contida. (SANTOS, 1999).

A garantia de uma educação com igualdade e respeito às diferenças é o objetivo que as políticas criadas para concretizar os direitos fundamentais devem alcançar. A educação é um dos direitos garantidos constitucionalmente a todos os brasileiros e estrangeiros residentes neste país, independentemente de raça, sexo, idade e condição física ou mental, pois toda discriminação e exclusão institucional-educacional é vedada.

Estabelece o artigo 206, I, da Constituição Federal/88, que:

"Art. 206. O ensino será ministrado com base nos seguintes princípios: 
I - igualdade de condições para o acesso e permanência na escola; [...]".

O artigo 208, III, do mesmo diploma legal, por sua vez, dispõe que:

"Art. 208. O dever do Estado com a educação será efetivado mediante a garantia de: [...]; III - atendimento educacional especializado ${ }^{3}$ aos portadores de deficiência, preferencialmente na rede regular de ensino; [...]"4

É inspirada nessa garantia educacional que surgiu a política nacional de inclusão, que vem causando diversas discussões por se tratar de uma situação nova e de difícil aplicabilidade.

Nesse sentido é o entendimento de Mazzotto (2001, p. 15):

A defesa da cidadania e do direito à educação das pessoas portadoras de deficiência é atitude muito recente em nossa sociedade. Manifestandose através de medidas isoladas, de indivíduos ou grupos, a conquista e o reconhecimento de alguns direitos dos portadores de deficiência podem ser identificados como elementos integrantes de políticas sociais, a partir de meados deste século.

São muitos os desafios da inclusão das pessoas com deficiência na rede regular de ensino. Essa inclusão se trata do acesso, ingresso e permanência dos referidos alunos em nossas escolas como bons discentes, e não como números de matrículas ou como mais um aluno na sala de aula do ensino regular. É preciso uma presença integrada com os demais colegas, de forma participativa, de modo a compartilhar a experiência de pertencer ao meio que se busca a integração. (CARVALHO, 2003, p. 101).

3 "Trata-se do atendimento que é necessariamente diferente do ensino escolar e que é indicado para melhor suprir as necessidades e atender as especificidades dos alunos com deficiência. Ele inclui, principalmente, instrumentos necessários à eliminação das barreiras que as pessoas com deficiência têm para relacionar-se com o ambiente externo." (FÁVERO; PANTOJA; MANTOAN, 2007, p. 26).

$4 \quad$ "O inciso contém importante programa, porém dificilmente realizável no Brasil”. (BULOS, 2002, p. 1.245). 
Neste contexto, o papel da escola é, sem sombra de dúvidas, importantíssimo na formação de todo e qualquer cidadão, principalmente do portador de necessidade especial. É a partir dela que o indivíduo passa a interagir com a sociedade, ou seja, com um grupo de pessoas estranhas a sua família.

Essa inclusão deve ocorrer desde a educação infantil, com uma escola com profissionais orientados para lidar com as crianças portadoras necessidades especiais e com quaisquer problemas no desenvolvimento, com um espaço adequado, rico em estímulos visuais, auditivos e outros. (FÁVERO; PANTOJA; MANTOAN, 2007, p. 38).

Assim, se a inclusão do aluno com deficiência se der no início de sua jornada escolar, será mais fácil de enfrentar as séries subsequentes e ele não terá defasagens no seu aprendizado.

Não se trata de uma questão simples, pois vivemos numa sociedade em que há crescente falta de respeito, discriminação negativa, competição, corrupção, marginalização e exclusão. Aliás, a sociedade que deveria ter como princípio a igualdade e a solidariedade é quem fecha as portas, não só da educação como do mercado de trabalho, aos portadores de necessidades especiais.

Os desafios por que passam as pessoas deficientes diante do isolamento social, são semelhantes aos preceitos da luta pela dissolução de falsos valores éticos que amparam e autenticam a sociedade capitalista apoiada na desigualdade social, a qual acaba deixando um ser humano contra o outro, extinguindo a singularidade e a subjetividade. (SILVA; VIZIM, 2003, p. 102).

Mas, felizmente, a sociedade aos poucos está tomando consciência de que as diferenças entre uma pessoa e outra não as tornam melhores nem piores, mas sim, simplesmente diferentes.

De acordo com o acima exposto e nas próprias palavras Bolonhini (2004, p. 25):

O aprendizado escolar para o portador de necessidade especial é 'a chave que abre a porta' para 
a verdadeira integração social. Daí a necessidade da eliminação de barreiras arquitetônicas, da boa orientação didático-pedagógica, da política escolar de inclusão e, portanto, do preparo e aceitação por parte do ente escolar dos cidadãos portadores de deficiência.

Por outro lado, os professores e demais profissionais na área da educação estão se vendo, muitas vezes, despreparados para realizar a inclusão desses alunos na rede regular de ensino. Dispõe o art. 59, III da Lei de Diretrizes e Bases da Educação Nacional:

Art. 59. Os sistemas de ensino assegurarão aos educandos com necessidades especiais: [...] III - professores com especialização adequada em nível médio ou superior, para atendimento especializado, bem como professores do ensino regular capacitados para a integração desses educandos nas classes comuns; [...].

Questiona-se, então, se efetivamente há professores com especialização adequada e se os demais professores estão capacitados nos termos do artigo acima mencionado.

É preciso preparar os professores, imediatamente, para realizar o processo de inclusão. Assim, eles poderão aceitar e se relacionar com todos os alunos, com suas diferenças e necessidades individuais, revisando, desta forma, antigas concepções e paradigmas educacionais, possibilitando o desenvolvimento cognitivo, cultural e social de todos os alunos.

Nesse contexto, os professores das escolas inclusivas são responsáveis pelo processo de aprendizagem de todos os alunos, inclusive, dos alunos com necessidades especiais. Entretanto, em algumas regiões pode não haver professor especializado para oferecer apoio pedagógico a esses alunos, mas isso não pode se transformar num impedimento para que uma criança ou adolescente com deficiência frequente a escola. Além disso, é preciso que a escola ofereça períodos de capacitação aos professores de classes comuns, reuniões de estudo com os professores especiali- 
zados, com supervisão da Delegacia e Coordenadoria de Ensino da região em que a escola se encontra. É necessário ainda, que a escola ofereça ao aluno deficiente espaço físico adequado, condições para facilitar sua melhor locomoção e recursos e equipamentos específicos para atender suas necessidades. (PAULA; COSTA, 2007, p. 15, 17, 18).

De acordo com MANTOAN; GOMES; FERNANDES; BATISTA; SALUSTIANO; e FIGUEIREDO (2007, p. 16 -18):

Se as escolas não se reorganizarem para atender a todos os alunos, indistintamente, a exclusão generalizada tenderá a aumentar, provocando cada vez mais queixas vazias e maior distanciamento da escola comum dos alunos que supostamente não aprendem. [...] Ao invés de adaptar e individualizar/diferenciar o ensino para alguns, a escola comum precisa recriar suas práticas, mudar suas concepções, rever seu papel, sempre reconhecendo e valorizando as diferenças. [...] Para conseguir trabalhar dentro de uma proposta educacional inclusiva, o professor comum precisa contar com o respaldo de uma direção escolar e de especialistas (orientadores, supervisores educacionais e outros), que adotam um modo de gestão escolar, verdadeiramente participativa e descentralizada.

Logo, a escola, frente a essa inclusão, tem o dever de ir à busca dos meios, de materiais e de profissionais adequados para estabelecer um ambiente satisfatório a todos os alunos, independentemente de suas características físicas, psíquicas e/ ou mentais.

Tendo em vista que, infelizmente, a maioria das escolas regulares se classificam como "despreparadas" para receber os alunos portadores de necessidades especiais, vez que muitos desses alunos nunca frequentou a escola de ensino regular, as escolas especializadas devem ajudar oferecendo apoio aos professores das escolas comuns. (FÁVERO; PANTOJA; MANTOAN, 2007, p. 32). 
Como este artigo é direcionado ao portador de deficiência auditiva, é interessante expor a definição da referida deficiência, bem como as peculiaridades educacionais dos alunos com este problema.

A deficiência auditiva se trata de uma redução da capacidade perceptiva normal de sons. É considerada surda a pessoa que não tem audição funcional em sua vida comum e parcialmente surdo a pessoa que tem audição funcional, mesmo que use prótese auditiva. Calcula-se que, no mínimo, uma a cada mil crianças nasce com surdez profunda, sendo que outras desenvolvem problemas auditivos durante a vida, resultantes das mais diversas causas. As deficiências auditivas surgidas tardiamente vêm causando muita preocupação tocante a comunicação, eis que a pessoa utilizava a Língua Portuguesa, e, com o seu problema, terá a necessidade de se adaptar à nova maneira de falar e de compreender o que lhe dizem. (UNITINS; EADCON, 2007, p. 9).

A deficiência auditiva é um dos problemas mais desafiadores dentro da educação, uma vez que atrapalha a recepção da linguagem e a sua produção. Assim, a maior dificuldade para as pessoas portadoras de deficiência auditiva é a comunicação, que dificulta sua convivência com as demais pessoas e a sua inserção social. O desenvolvimento intelectual, social e emocional da pessoa surda, está ligado a atitudes da comunidade e dos pais. Mais um ponto importante para o desenvolvimento do surdo é o diagnóstico, que quanto mais precocemente for realizado e iniciado o trabalho educacional, melhor será seu desenvolvimento pessoal e social. (TESSARO, 2005, p. 36-37).

A escola comum deve viabilizar a educação dos alunos com surdez com um atendimento educacional especializado e com um ensino contemplando a Libras (língua brasileira de sinais) e um ensino em Libras com Língua Portuguesa. Têm surgido muitos debates sobre a educação escolar para os deficientes auditivos. A educação escolar inclusiva é um desafio que tem como princípio norteador o direito de acesso ao conhecimento 
e ao atendimento educacional especializado. (DAMÁSIO, 2007, p. 15).

Os estudantes portadores de deficiência auditiva devem ser incluídos no ensino regular, sendo que isso deve ocorrer desde cedo, através de recursos que ajudem a superar barreiras no caminho educacional, exercendo, assim, a cidadania, conforme os princípios constitucionais pátrios. Para tanto, a inclusão de pessoa com surdez na escola regular precisa do auxílio de meios e ferramentas de aprendizagem. (DAMÁSIO, 2007, p. 14).

O trabalho desenvolvido no atendimento educacional especializado promove a acessibilidade à comunicação, à informação e à educação. Tendo uma experiência visual, os surdos se comunicam e aprendem através de formas alternativas de comunicação com símbolos, encontrando na língua de sinais seu principal meio de efetivação. Desta forma, os recursos multifuncionais para os alunos surdos ou com pouca audição, complementam o currículo escolar, em período diferente ao da classe regular, o que é necessário para os alunos com essas peculiaridades na comunicação, fazendo com que aprendam instrumentos linguísticos necessários para inclusão educacional e social. (BASTOS, 2007, p. 485).

\section{AAPLICABILIDADEDAINCLUSÃODOSPORTADORES DE DEFICIÊNCIA AUDITIVA NA REDE REGULAR DE ENSINO DO MUNICÍPIO DE CAMPOS NOVOS - SC}

O presente artigo tem o objetivo de identificar os verdadeiros problemas escolares por que passam os alunos com deficiência auditiva.

É importante esclarecer inicialmente, que foi realizada uma visita em seis escolas do Município de Campos Novos, a fim de investigar e constatar a situação dos alunos portadores de deficiência auditiva que estão inseridos na rede regular de ensino do referido município. Foi realizada uma entrevista com os diretores das escolas, sendo três públicas e três particulares. 
As escolas e visitadas possuem o seguinte número de alunos e de alunos portadores de deficiência auditiva:

\begin{tabular}{|c|c|c|}
\hline Escola & $\begin{array}{c}\text { Total de } \\
\text { Alunos }\end{array}$ & $\begin{array}{c}\text { Alunos Portadores } \\
\text { de Deficiência } \\
\text { Auditiva }\end{array}$ \\
\hline Escola Pública "A" & 1270 & 6 \\
\hline Escola Pública "B" & 870 & 1 \\
\hline Escola Pública "C" & 822 & 0 \\
\hline Escola Privada "D" & 453 & 0 \\
\hline Escola Privada "E" & 190 & 0 \\
\hline Escola Privada "F" & 90 & 0 \\
\hline
\end{tabular}

Há cerca de cinco anos os alunos portadores de deficiência auditiva estão frequentando a rede regular de ensino do município, conforme constatado por meio de conversa informal com diretores e professores.

Já nas escolas "C", "D”, "E" e "F", não há alunos com esse tipo de deficiência no momento, devido à falta de procura ou, até mesmo, a própria recusa indireta das instituições de ensino. Diante desse fato, foi questionado a um dirigente de uma das escolas privadas entrevistadas, que preferiu ficar no anonimato, o porquê da falta de alunos portadores de deficiência auditiva matriculados, uma vez que, conforme exposto em outro momento deste trabalho, cerca de $10 \%$ da população brasileira é constituída por pessoas portadoras de alguma deficiência. Como resposta ao questionamento feito, o diretor da escola disse que não realiza a matrícula desses alunos, pois não tem aparatos e professores especializados para educá-los. Além disso, disse que cobra dos pais de alunos deficientes auditivos um valor extra para que haja um intérprete de Libras na sala de aula, como forma de "recusa indireta" do aluno.

Logo, seguindo à risca o texto legal, a referida escola, ao negar a matrícula a alunos em razão de suas deficiências, cometeu, em tese, o crime previsto no art. $8^{\circ}$, I, da Lei no 7.853/89, o qual dispõe que: 
Art. $8^{\circ}$ Constitui crime punível com reclusão de 1 (um) a 4 (quatro) anos, e multa:

I - recusar, suspender, procrastinar, cancelar ou fazer cessar, sem justa causa, a inscrição de aluno em estabelecimento de ensino de qualquer curso ou grau, público ou privado, por motivos derivados da deficiência que porta;

$[\ldots]$

Agora, se outra escola, sabendo que o aluno foi rejeitado por uma determinada instituição de ensino devido a sua condição (portador de deficiência), não denuncia tal fato aos órgãos competentes, igualmente incorrerá na mesma pena do art. 8o, I, da Lei no 7.853/89. (FÁVERO; PANTOJA; MANTOAN, 2007, p. 32).

Nesse sentido o art. 2, da Resolução no 2/2001, do Conselho Nacional da Educação, dispõe que:

Art. 20 Os sistemas de ensino devem matricular todos os alunos, cabendo às escolas organizar-se para o atendimento aos educandos com necessidades educacionais especiais, assegurando as condições necessárias para uma educação de qualidade para todos.

Neste enfoque, os diretores das escolas têm um importante papel para fazer com que as escolas dêem mais atenção às pessoas portadoras de necessidades especiais. Para isso, eles devem ter independência e treinamento para que possam incluir esses alunos. Eles devem ser incentivados a administrarem a escola com métodos de aprendizagem mais abrangentes e flexíveis, com a cooperação de todos os integrantes da escola. (BOLONHINI, 2004, p. 319).

O despreparo (total ou parcial) das escolas vai contra o princípio da escola inclusiva, onde todos devem aprender juntos, independentemente dos problemas ou peculiaridades de cada indivíduo. 
As escolas inclusivas têm que ter conhecimento e dar conta dos diferentes tipos de necessidades dos seus alunos, garantindo um ensino de qualidade a todos, por meio de um currículo adequado, disposições de organização, planos de ensino, utilização de recursos, participação da comunidade e, principalmente, de profissionais com especialização e capazes de promover a inclusão.

Sobre a idéia de especialização, o art. 8, I, IV e V, da Resolução no 2/2001, do Conselho Nacional da Educação, assim estabelece:

Art. $8^{\circ}$ As escolas da rede regular de ensino devem prever e prover na organização de suas classes comuns:

I - professores das classes comuns e da educação especial capacitados e especializados, respectivamente, para o atendimento às necessidades educacionais dos alunos;

$[\ldots]$

IV - serviços de apoio pedagógico especializado, realizado, nas classes comuns, mediante:

a) atuação colaborativa de professor especializado em educação especial;

b) atuação de professores- intérpretes das linguagens e códigos aplicáveis;

c) atuação de professores e outros profissionais itinerantes intra e interinstitucionalmente;

d) disponibilização de outros apoios necessários à aprendizagem, à locomoção e à comunicação.

$\mathrm{V}$ - serviços de apoio pedagógico especializado em salas de recursos, nas quais o professor especializado em educação especial realize a complementação ou suplementação curricular, utilizando procedimentos, equipamentos e materiais específicos;

[...]. 
$\mathrm{O}$ art. $18, \S 1^{\circ}, \S 2^{\circ}, \S 3^{\circ}$ e $\$ 4^{\circ}$, do mesmo diploma legal, regulamenta o que vem a ser o chamado professor capacitado/ especializado:

Art. 18. Cabe aos sistemas de ensino estabelecer normas para o funcionamento de suas escolas, a fim de que essas tenham as suficientes condições para elaborar seu projeto pedagógico e possam contar com professores capacitados e especializados, conforme previsto no Artigo 59 da LDBEN e com base nas Diretrizes Curriculares Nacionais para a Formação de Docentes da Educação Infantil e dos Anos Iniciais do Ensino Fundamental, em nível médio, na modalidade Normal, e nas Diretrizes Curriculares Nacionais para a Formação de Professores da Educação Básica, em nível superior, curso de licenciatura de graduação plena.

$\S 1^{\circ}$ São considerados professores capacitados para atuar em classes comuns com alunos que apresentam necessidades educacionais especiais aqueles que comprovem que, em sua formação, de nível médio ou superior, foram incluídos conteúdos sobre educação especial adequados ao desenvolvimento de competências e valores para:

I - perceber as necessidades educacionais especiais dos alunos e valorizar a educação inclusiva;

II - flexibilizar a ação pedagógica nas diferentes áreas de conhecimento de modo adequado às necessidades especiais de aprendizagem;

III - avaliar continuamente a eficácia do processo educativo para o atendimento de necessidades educacionais especiais;

IV - atuar em equipe, inclusive com professores especializados em educação especial.

$\S 20$ São considerados professores especializados em educação especial aqueles que desenvolveram competências para identificar as necessidades educacionais especiais para definir, implementar, 
liderar e apoiar a implementação de estratégias de flexibilização, adaptação curricular, procedimentos didáticos pedagógicos e práticas alternativas, adequados ao atendimentos das mesmas, bem como trabalhar em equipe, assistindo o professor de classe comum nas práticas que são necessárias para promover a inclusão dos alunos com necessidades educacionais especiais.

§ 30 Os professores especializados em educação especial deverão comprovar:

I - formação em cursos de licenciatura em educação especial ou em uma de suas áreas, preferencialmente de modo concomitante e associado à licenciatura para educação infantil ou para os anos iniciais do ensino fundamental;

II - complementação de estudos ou pós-graduação em áreas específicas da educação especial, posterior à licenciatura nas diferentes áreas de conhecimento, para atuação nos anos finais do ensino fundamental e no ensino médio;

$\S 4^{\circ}$ Aos professores que já estão exercendo o magistério devem ser oferecidas oportunidades de formação continuada, inclusive em nível de especialização, pelas instâncias educacionais da União, dos Estados, do Distrito Federal e dos Municípios.

$\mathrm{Na}$ educação de pessoas surdas é muito importante a presença de um intérprete, o qual tem a função de repassar as informações do professor para o aluno, facilitando o aprendizagem deles. Desta forma o professor poderá dar seus conteúdos sem que haja a necessidade de dar atenção especial ao aluno surdo. (Unitins; Eadcon, 2007, p. 39).

Diante disso, foi perguntado aos diretores se a escola tem um intérprete de Libras-Língua Brasileira de Sinais, sendo que apenas nas escolas "A" e "E" há intérprete capaz de se comunicar fluentemente em Libras. E, somente na escola Pública "A" há professores com pós-graduação em Libras. 
Já nas escolas "B", "C", "D" e "F", não há intérprete algum. Todavia, há alguns professores com cursos básicos de Libras em todas as escolas, que, geralmente tem duração aproximada de 20hs/aulas e são oferecidos pelo Estado ou por uma Associação do Município. O curso básico permite que o professor tenha uma noção geral dos símbolos, mas não permite que o docente efetivamente consiga repassar conhecimentos aos alunos portadores de deficiência auditiva, conforme informações colhidas com alguns professores.

Segue abaixo os dados acerca da capacitação dos professores das escolas visitadas:

\begin{tabular}{|c|c|c|c|}
\hline Escola & $\begin{array}{c}\text { Quantidade } \\
\text { de } \\
\text { Professor } \\
\text { Intérprete }\end{array}$ & $\begin{array}{c}\text { Quantidade } \\
\text { de Professor } \\
\text { com Pós- } \\
\text { Graduação } \\
\text { em Libras }\end{array}$ & $\begin{array}{c}\text { Quantidade } \\
\text { Professor } \\
\text { com curso } \\
\text { básico de } \\
\text { Libras }\end{array}$ \\
\hline Escola Pública "A" & 3 & 4 & 15 \\
\hline Escola Pública "B" & 0 & 0 & 3 \\
\hline Escola Pública "C" & 0 & 0 & 2 \\
\hline Escola Privada "D" & 0 & 0 & 1 \\
\hline Escola Privada "E" & 1 & 0 & 3 \\
\hline Escola Privada "F" & 0 & 0 & 1 \\
\hline
\end{tabular}

Diante dessas informações, pode-se perceber que as escolas estão pouco preparadas para receber os alunos portadores de deficiência auditiva, salvo a escola Pública "A", que se mostrou preparada para a inclusão.

Salienta-se que mesmo diante do fato da escola não ter alunos com essa deficiência, ela deveria estar preparada para recebê-los, vez que não podem, em hipótese alguma, recusar a matrícula de alunos em razão de suas deficiências.

Constatou-se, ainda, que os poucos docentes que são capacitados para educar esses alunos, fizeram isso por iniciativa e conta própria.

O inciso III, do §3॰ do art. 87, da LDBEN, determina que o Distrito Federal, o Estado, o Município, e, supletivamente, a União, devem: 
“[...] III - realizar programas de capacitação para todos os professores em exercício, utilizando também, para isto, os recursos da educação à distância; [...]"

No entanto, conforme informações colhidas em um momento de interação com os docentes (da escola pública "A") foi revelado que o estado de Santa Catarina e o município de Campos Novos ofertam, raramente, aos professores cursos de capacitação complementar, mas que os mesmos são de curta duração, não possibilitando educar, de fato, os alunos portadores de deficiência auditiva. Revelaram, ainda, que o ideal seria a oferta de cursos mais extensos, como especializações/ pós-graduações, que dêem suporte para promover a inclusão, e não somente dar uma noção básica, como nos cursos de capacitação. A dificuldade encontrada pelos professores é que a maioria dessas especializações/pós-graduações são pagas, ou seja, o Estado não oferece gratuitamente, o que se torna mais um empecilho para a inclusão.

Como se percebe acima, grande parte das instituições não possuem aparatos e profissionais suficientes para lidar com os educandos portadores de deficiência auditiva, fato este que não corresponde ao disposto no art. 59, I, da LDBEN, o qual preconiza que:

"Art. 59. Os sistemas de ensino assegurarão aos educandos com necessidades especiais: I - currículos, métodos, técnicas, recursos educativos e organização específicos, para atender às suas necessidades; [...]".

Diante disso, questionou-se aos dirigentes das escolas se realizam reuniões (não esporádicas) com temáticas sobre a inclusão dos alunos portadores de necessidades especiais, bem como se a escola possui recursos didáticos específicos para alunos com deficiência auditiva, sendo que as respostas foram elucidadas no seguinte quadro: 


\begin{tabular}{|c|c|c|}
\hline Escola & $\begin{array}{c}\text { Reuniões Sobre o } \\
\text { Tema }\end{array}$ & $\begin{array}{c}\text { Recursos } \\
\text { Didáticos }\end{array}$ \\
\hline Escola Pública "A" & Sim & Sim \\
\hline Escola Pública "B" & Não & Não \\
\hline Escola Pública "C" & Não & Não \\
\hline Escola Privada "D" & Não & Não \\
\hline Escola Privada "E" & Não & Não \\
\hline Escola Privada "F" & Não & Não \\
\hline
\end{tabular}

Com exceção da escola Pública "A", todas as outras não realizam reuniões para discussão do tema, muito menos possuem recursos didáticos disponíveis para os alunos com deficiência auditiva. Portanto, a escola Pública "A" é um exemplo de escola inclusiva, pois, além de possuir professores especializados e capacitados para trabalhar com alunos portadores de deficiência auditiva, possui uma série de recursos didáticos, tais como, Livros didáticos do Projeto Pitanguá em Libras, DVDs, dicionários de Libras, jogos adaptados e vocabulários com figuras e sinais em Libras.

A escola Pública "C" justificou que a falta de materiais didáticos para trabalhar com alunos com deficiência auditiva, deve-se ao fato do Município não fornecer os mesmos, apesar dos inúmeros pedidos que são realizados pela escola.

Outro ponto importante de se destacar, é que a instituição de ensino Público "A" criou dentro da escola um centro do chamado SAED (Serviço de Atendimento da Especializado), o qual é subdividido entre o SAED/DA (Serviço de Atendimento da Especializado para Deficientes Auditivos) e o SAED/DV (Serviço de Atendimento da Especializado para Deficientes Visuais). Os alunos com essas necessidades educacionais especiais frequentam o SAED duas vezes por semana com atendimento de duas horas. Além disso, alunos de outras escolas também utilizam o serviço. A locomoção é feita através de uma parceria entre prefeitura e a Associação de Apoio a Deficientes Auditivos e Visuais da cidade. $\mathrm{O}$ diretor da escola afirma que houve dificuldades no início do processo de inclusão de portadores de necessidades especiais no ensino regular, mas houve 
muitos avanços e a receptividade de professores e alunos sempre foi positiva.

Assim, como visto, a escola Pública "A" é a única que demonstrou estar preparada para a promoção da inclusão dos alunos portadores de deficiência auditiva, concernente ao que foi questionado e observado nesta pesquisa.

Na sociedade atual, a escola tem uma importante função dentro da aprendizagem, eis que alguns conhecimentos socialmente adquiridos são repassados as pessoas unicamente dentro da escola. Diante disso, ela é a porta de entrada das pessoas na sociedade, visto que para o sujeito poder compreender e se encaixar nos espaços sociais é preciso utilizar os ensinamentos que a escola proporciona. Entretanto, para a construção de uma escola inclusiva é necessário um conjunto de ações advindas de pessoas e órgãos que assumam a responsabilidade de alterar as situações prejudiciais à educação da população brasileira. (VARGAS; BECHE; SILVA, 2003, p. 69 e 71).

É evidente a necessidade de uma reestruturação das escolas que foram visitadas para que a inclusão ocorra na prática. Deve haver uma reflexão sobre o ensino inclusivo, para que, desse modo, se encontrem meios que surtam efeitos na atual situação da educação. Deve-se ter em mente que é necessário ir à busca dos direitos, exigindo dos órgãos governamentais o cumprimento da lei, no que tange ao processo de inclusão dos alunos portadores de necessidade especiais.

É preciso ir à busca da "inclusão real" dos alunos portadores de necessidades especiais na rede regular de ensino, ou seja, quando os alunos portadores de deficiência são colocados junto aos demais alunos para aprender e ser avaliados de maneira igualitária. Não basta a simples "inclusão aparente", que é quando os alunos portadores de deficiência são colocados junto aos demais apenas para responder um anseio da sociedade, mas na verdade estão lá sem aprender e sem condições de evoluir para as próximas séries. 
A visita nas escolas evidenciou a necessidade de mais investimentos na educação de maneira geral, uma vez que a falta de infra-estrutura, recursos materiais e humanos prejudicam o aluno que frequenta a rede regular e todos os integrantes do sistema educacional. Tanto na rede privada, como na rede pública de ensino, há falta de investimentos e incentivos para a promoção da inclusão de portadores de deficiência auditiva e dos demais portadores de necessidades educacionais especiais. Esses problemas poderão ter fim quando ocorrer o cumprimento integral dos princípios, leis, documentos e declarações internacionais que estabelecem diretrizes sobre a inclusão.

Conforme salienta Bolonhini (2004, p. 191), apesar da política da inclusão educacional ser o vetor para a educação dos portadores de necessidades especiais, há muito que se fazer para se concretizar tal ideal no Brasil. A ausência de profissionais do ensino capacitados, de ambientes adaptados e de uma consciência sócio-educacional acabam sendo impedimentos para as instituições de ensino que pretendem participar do processo de inclusão, prevalecendo, assim, a exclusão.

Os agentes educacionais devem, antes de fazer discursos, assumir o compromisso de incluir esses alunos na prática, a fim de tornar o sistema educacional apto a fornecer um ensino de qualidade para todos os educandos, inclusive, os portadores de necessidades especiais. Para que isso ocorra é preciso que haja uma conscientização e um engajamento de todos (professor, escola, aluno, comunidade, etc.) em busca de uma educação de qualidade. (TESSARO, 2005, p. 158).

A educação, um dos mais importantes direitos sociais, é fundamental para a ocorrência de outros direitos fundamentais. Ela não consiste somente no ato de informar, mas sim, na conscientização e preparação do ser humano para ter um pensamento crítico.

Magalhães (2002, p. 280) dispõe que a Constituição Federal/88, no seu art. 205, traz a educação como um "direito de todos e dever do Estado e da família, com a colaboração da 
sociedade. [...] O dever do Estado de educar significa a preparação do indivíduo para o exercício da cidadania e a vida em sociedade [...]".

Conforme se observou por meio da visita as escolas, a garantia constitucional à educação, mais especificamente à inclusão dos portadores de deficiência auditiva na rede regular de ensino do município de Campos Novos, apesar de possuir eficácia jurídica plena, não possui eficácia social, que é quando a norma, na realidade, tem seus mandamentos observados pelos seus respectivos destinatários.

Como as escolas e os professores não se mostraram totalmente preparados para realizar a inclusão dos educandos deficientes auditivos no ensino regular (concernente ao que foi observado in loco), não há no caso concreto uma correspondência da norma constitucional ao comportamento social. Assim, a eficácia social vai depender da realização de sucessivas implementações e a consequente execução de programas governamentais, bem como de políticas públicas socioeconômicas.

\section{CONCLUSÃO}

Este trabalho teve aporte teórico no direito constitucional, pois tratou de uma série de questões acerca do tema, como direitos humanos, direitos fundamentais, princípio da igualdade e eficácia dos direitos fundamentais.

Objetivou-se com o presente artigo científico analisar o tratamento dispensado às pessoas portadoras de deficiência auditiva pelo ordenamento jurídico brasileiro, especialmente quanto ao seu direito à educação, preferencialmente na rede regular de ensino.

Foi realizada uma visita em seis escolas do município de Campos Novos, e entrevistados os respectivos dirigentes.

O foco deste trabalho, portanto, foi investigar a situação dos alunos portadores de deficiência auditiva que estão frequentando o ensino regular do município de Campos Novos, a fim 
de fazer uma ponte para identificar a situação dos deficientes auditivos de modo geral, ou seja, dos que estão inseridos no ensino regular de todo o país.

São muitas as dificuldades envolvidas no processo de inclusão dos educandos deficientes auditivos e, conforme identificado na pesquisa realizada, se destaca o despreparo dos professores, que não se mostraram totalmente capacitados para educar esses alunos, assim como a falta de incentivo das instituições de ensino regular.

Verificou-se a ocorrência de falhas tanto das escolas, como dos professores, dos órgãos governamentais, dos pais e da comunidade, os quais, ainda, não estão movimentados para este ideal.

Pode-se observar que os agentes educacionais que compõe as escolas públicas estão mais animados e participativos para que a inclusão seja realizada. Contudo, também foi constatada a ausência de incentivo do Estado, que é o financiador da educação pública.

Já nas escolas privadas, não se percebeu o mesmo ânimo das públicas, uma vez que sendo o ensino pago estas instituições deveriam estar preparadas para receber todo o tipo de clientela (alunos).

Assim, muito embora as intenções sejam boas, as atitudes vistas na realidade apontam para caminhos diversos.

Há muito que se fazer ainda para a concretização da inclusão dos portadores de deficiência auditiva na rede regular de ensino, uma vez que restou demonstrado que a garantia constitucional da inclusão não está sendo totalmente realizada na prática. O que comprova que a norma constitucional (direito à educação, preferencialmente, na rede regular de ensino) é carente de eficácia social (concretização da lei ao fim a que ela se destina).

A pesquisa realizada conseguiu atingir os objetivos almejados e os resultados poderão contribuir de forma positiva para a promoção e aprimoramento da inclusão dos portadores de deficiência auditiva que frequentam o ensino regular do município de Campos Novos. 
Por fim, conclui-se que não é mudando de lugar que os alunos portadores de necessidades educacionais especiais serão automaticamente incluídos e aprenderão de maneira igual aos demais alunos. Mas, a simples mudança de lugar, ou seja, a passagem do aluno da escola especial para a escola comum, já significa uma atitude que abrirá as portas da aspirada educação inclusiva.

\begin{abstract}
This article aims to study the situation of people with hearing impairment, making an analysis about the inclusion of individuals into the regular education of the city of Campos Novos, SC. Was sought through a literature search and field, how is giving the school inclusion of students with special educational needs in order to find out if schools and teachers in the focus of the research council are prepared to realize that the inclusion the 1988 Federal Constitution establishes. It was concluded that there is much still to do for effective inclusion, since the schools visited were not able to fully promote this constitutional guarantee. Thus, it was observed that the constitutional rule, despite being a fundamental right (right to education) is lacking in social efficiency, it is the implementation of the law for the purpose it was intended.
\end{abstract}

Keywords: Hearing impaired. Inclusion. Education. Regular school system.

\title{
REFERÊNCIAS
}

AMORIM, Pierre Souto Maior Coutinho de. Sistema de Cotas. Tribunal de Justiça do Estado de Rondônia, Rondônia, artigo criado em 2002 e atualizado em 21 de março de 2003. Disponível em: 〈http://www.tj.ro.gov. br/emeron/sapem/2003/MAIO/0905/ARTIGOS/A01.htm>. Acesso em: 01 mar. 2011.

BASTOS, Vivian de Camargo. Normal Superior: séries iniciais do ensino fundamental. 2007. 
BOLONHINI Júnior, Roberto. Portadores de Necessidades Especiais: as principais prerrogativas dos portadores de necessidades especiais e a legislação brasileira. São Paulo: Arx, 2004.

Brasil. Constituição Federal: república federativa do brasil de 1988. Diário Oficial da União, Brasília, DF: Senado Federal, 1988.

Brasil. Ministério da Educação. Lei de Diretrizes e Bases da Educação Nacional. Lei 9.394 de 20 de dezembro de 1996.

. Brasil. Lei $n^{\circ} 7.853$, de 24 de outubro de 1989. Diário Oficial da União, Brasília, DF. Disponível em: <http://www.planalto.gov.br/ ccivil_03/LEIS/L7853.htm>. Acesso em: 01 mar. 2011.

Brasil. Resolução no 02/2001 de 11 de setembro de 2001. Câmara de Educação Básica do Conselho Nacional de Educação, Brasília, DF. Disponível em: <http://portal.mec.gov.br/cne/arquivos/pdf/CEB0201. pdf>. Acesso em: 01 mar. 2011.

BULOS, Uadi Lammêgo. Constituição Federal Anotada. 4 ed. São Paulo: Saraiva, 2002.

CARVALHO, Rosita Edler Carvalho. Removendo barreiras para a aprendizagem. Porto Alegre: Mediação, 2003.

COMPARATO, Fábio Konder. A Afirmação Histórica dos Direitos Humanos. 3 ed., 2003.

DAMÁSIO, Mirlene Ferreira Macedo. Atendimento Educacional Especializado: pessoa com surdez. São Paulo: MEC/SEESP, 2007.

DINIZ, Maria Helena. Norma Constitucional e seus Efeitos. 5 ed., São Paulo: Saraiva, 2001.

FÁVERO, Eugênia Augusta Gonzaga; PANTOJA, Luíza de Marillac P.; MANTOAN, Maria Teresa Eglér. Atendimento Educacional Especializado: aspectos legais e orientações pedagógicas. São Paulo: MEC/SEESP, 2007.

FERREIRA, Luiz Antonio Miguel. Educação, deficiência e Cidadania. Buscalegis, Justiça: órgão do ministério público de São Paulo. 2006, Disponível em: <http://buscalegis.ccj.ufsc.br/arquivos/civel\%2035.pdf>. Acesso em: 01 mar. 2011.

HERKENHOFF, João Baptista. Gênese dos Direitos Humanos. 2 ed., São Paulo: Santuário, 2002. 
MAGALHÃES, José Luiz Quadros. Direito Constitucional. 2 ed., Belo Horizonte: Mandamentos, 2002.

MANTOAN, Maria Teresa Egler; GOMES, Adriana Limaverde; FERNANDES, Anna Costa; BATISTA, Cristina Abranches Mota; FIGUEIREDO, Rita Vieira; SALUSTIANO, Dorivaldo Alves. Deficiência Mental. São Paulo: MEC / SEESP, 2007.

MORAES, Alexandre de. Direito Constitucional. 17 ed. São Paulo: Atlas, 2005.

. MORAES, Alexandre de. Direitos Humanos Fundamentais. Vol. 3 , São Paulo: Atlas, 1997.

NUNES, Anelise Coelho. A Titulariedade dos Direitos Fundamentais na Constituição Federal de 1988. Porto Alegre: Livraria do Advogado, 2007.

PAULA, Ana Rita de; COSTA, Carmen Martini. A Hora e a Vez da Família em uma Sociedade Inclusiva. 1 ed., Brasília: Ministério da Educação, Secretaria de Educação Especial, 2007.

Unitins; Eadcon. Pedagogia. Palmas: Educon, 2007.

RAMOS, André de Carvalho. Teoria Geral dos Direitos Humanos na Ordem Internacional. Rio de Janeiro: Renovar, 2005.

SANTOS, Marcos André Couto. A efetividade das normas constitucionais: as normas programáticas e a crise constitucional. 1999. Disponível em: <http:// jus2.uol.com.br/doutrina/texto.asp?id=4731>. Acesso em: 01 mar. 2011.

SARLET, Ingo Wolfgang. A eficácia dos Direitos Fundamentais. 8 ed., Porto Alegre: Livraria do Advogado, 2007.

SILVA, Shirley; VIZIM, Marli. Políticas Públicas: educação, tecnologias e pessoas com deficiências. São Paulo: Mercado de Letras, 2003.

TESSARO, Nilsa Sanches. Inclusão Escolar: concepções de professores e alunos da educação regular e especial. São Paulo: Casa do Psicólogo, 2005.

VARGAS, Gárdia; BECHE, Rose Clér Estivalete; SILVA, Solange Cristiana. Educação Especial e Aprendizagem. 2 ed., Florianópolis: UDESC Universidade do Estado de Santa Catarina, 2003. 